tho incicions, howerer, being made more treely, but not anried to far forwerds as to endanger the enterior arural, or 80 far back as 80 wound the sciatic berve. After the removal of the head of the femur, all loose pieces of necrosed bone are to be taken out, and then, by means of ordinary cutting or gouge Corceps, the acetabulum and other diseased ossoous structures out away piecemeal. In doing this, it will be found that the neerosed bone readily separates by means of the finger, or by the handle of a scalpel, from the subjacent soft structures; and the muscles and fescix lining the polvic bones, being thickened and infiltrated with lymph, effectually protect the conteined parts from all injury.

The result of excision of the hip.joint has to be considered from two points of view : 1 . So far as the mortality immedi. ately referrible to the operation is concerned; and 2. As to the utility of the limb that is left after its performance.

1. As to the fatality directly referrible to the operation itself. On this point it is diffenclt to speak with absolute accuracy at present, the statistics of all the operations not being beforo the profession; but, so far as my own experience is concerned, it is as follows. I have operated in seven cases. Of these, not one has proved fatal; three are now well and going about; two I have lost sight of, after their recovery and discharge from hospital ; and two have died, one eleven months and the other two years after the operation, from constitutional disease unconnected with it. When we consider that all these cases were instances of advanced femoral or acetabular cos. algia, which would speedily have proved fatal if not subjected to operation, we may with justice look upon them as successful $80 \mathrm{far}$ as the preservation of life was concerned. And, in this respect, excision of the head of the femur, or of the hip-joint, stands in a different position to similar operations practised on other joints. The surgeon excises the elbow, shoulder, or ankle, in order to restore a useful limb to the patient. Exci. sion of these joints is substitute for the loss of the limb by amputation-not, as in the case of the hip, for the loss of the life of the patient by continuance of hectic.

2. As to the utility of the limb left after excision of the head of the femur or the hip.joint. In estimating the utility of the limb left after excision of the hip.joint, we must compare it with the kind of member that would be left in the event of the patient surviving sufficiently long for a natural cure to result. It would be manifestly absurd to compare a limb which had become seriously crippled, diseased, and shortened, before any operation was undertaken, with one in which no morbid action had ever taken place. So also would it be unjust to compare it with the state of a limb left after a slight attack of coxalgia in which operation could never have become necessary or been contemplated. But, on comparing the result of operated cases with that of those which recover spontaneously, after caries and destructive disintegration of the upper epiphysis of the femur has existed for years, we shall find that the balance is by no means against those in which excision has been done. As I do not consider the operation necessary in cases of arthritic coxalgia, I do not compare the result of these cases with that of those operated on, but confine myself entirely to those in which there has been destructive bone-disease. In such cases as these, when, after years of prolonged suffering, recovery is at last accomplished by natural means, what is the condition of the limb that is left? Why, more or less com. pletely anchylosed at the hip, wasted, shortened to the extent of two or three inches, partially flexed upon the pelvis, adducted, with the knee possibly stiffened, semifiexed and advanced, the patient just able to put the toes to the ground, without the power of bearing upon or rotating the limb; but when he wishes to turn, twisting the whole pelvis by the aid of the greatly increased mobility of the lumbar spine.

After successful cxcision, the result is much more satisfactory, as may be seen by the accompanying drawing, or as you had an opportunity of witnessing in the boy on whom I had operated three years ago. The principal morbid appearance in the limb is its shortening to the extent usually of from two to three inches-to the extent, indeed, to which the preexisting disorganisation and dislocation of the head of the bone had previously reduced it. It is well nourished, straight, firm, and admits of easy and rapid progression. The anchylosis is fibrous, not osseous. The patient is then ensbled to flex the thigh on the pelvis, and to adduct it ; but, just as in cases that, have undergone a natural cure, the power of exiernal rotation and of abluction are lost, the molility of the lumbar spine compensating for the loss of these movements.

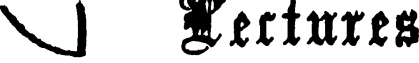

ox

\section{THE HISTORY OF MEDICINE.}

DELTVERED $A T$

THE GROSVENOR PIACE SCHOOL OF MEDICINE.

DX

ALEXANDER HENRY, M.D.

LECTURE III.

Circumstances favouring the Development of :Philosophy among the Greeks. Character of early Grecian Philosophy. Pythagoras. Alcmaon. Empedocles. Anaxagoras. Demo. critus. Heraclitus. Public Practice of Mledicine: its origin. Dispersion of the Crotona School. Democedes. Acron. Public Gymnasia: their influence on Medicine. Herodicus. Iccus. Summary.

In the last lecture, I gave a skotch of the practice of medicine as it is handed down to us as having been followed in the temples of Esculapius. I shewed that it ostensibly consisted in an appeal to the superstitious feelings of the people; and that the priests of the temples jealously retained all knowledge relating to the cure of disease within their own order. At the same time, I alluded to the fact, that it was a common custom to preserve records of the historios of the patients who had been under treatment; and $I$ also mentioned that certain of the temples were especially distinguished by the attention which their priests paid to the study of disease, and thet in themespecially in one of them - was laid the solid foundation of our system of medicine.

We now arrive at a period which is characterised bs a re markable change in the aspect of our science. After a period of some hundreds of years, in which medicine remained 8 mystic art, there appears a family of Asclepiads, who interweave with their own knowledge the learning which surrounds them in the external world, and at last give to the world a collection of treatises, containing a mass of medical knowledge which bas in all ages called forth the admiration, not only of the profession, but of the general historian. The doctrines and precepts taught in these treatises, which we commonly know as the works of Hippocrates, call for our careful and impartial examination; but, before entering on this, it is necessary that $I$ should bring before your notice the circumstances which led to their appearance, and to the advanced development of our science which is manifested in them, and comment on the causes which produced so great and salutary a revolution in the history of medicine.

So great an impulse could not well have been given to the progress of a science in any other country, at the time of which I am speaking, than in Greece. For the inhabitants of these other regions whose history has reached us were, in regard to knowledge, in a state of abject subservience to the teachings of their priests, from which their inactive mental constitution did not aid them to escape. Every phenomenon of nature, and every deviation from her ordinary course, were by the mass of the people regarded as the immediate effect of divine interference; and any inquiry into the causes of things was considered useless and superfluous, if not positively impious. We can well imagine the argument to have been applied, if occasion offered, to the study of the philosopby of nature, which is re. ported to have been used by the Caliph Omar, when asked in what way the Alexandrian library should be disposed of: "If the contents of the books agree with the writings of the Prophet, they are superfluous; if they contain anything contrary, they are impious."

In Greece, however, thought was free and active; indeed, what error there was lay rather in the opposite direction to that of other nations: for thought-that is to say, speculative philosophy - was often allowed to outstrip fact. But what is important is, that thought was not altogether fettered; and that popular prejudices, religious opinions, and social institutions, did not assign absolute limits beyond which the human infellect was not permitted to pass. The active Grecian mind, thus free to exercise itself, threw off all restraint; and the philusophers of that country arrived at the point which one might 
expect to reach, by profoundly inquiring into the causes of natural phenomena without a sufficient acquaintance with nature herself.

In seeking for the causes which effected so great a development of the Grecian intellect, and produced so marked a difference in the aspect of science in Greece from that which it presented in other nations, we bave to call to mind the circum. stances connected with the topographical, social, and political condition of the inhabitants of that country.

The situation and climate of the country were such as must promote the development of intellectual vigour and refined mental qualities. Another circumstance which would favour the progress of art and science, was the commercial intercourse which the Greeks of Ionia maintained with their neighbours the Lydians. The inhabitants of Samos, Ephesus, Miletus, and other towns of Ionia, thus acquiring wealth by commerce, were so far relieved of many of the cares of the body, as to be able to cultivate with profit their active minds. The education and mode of life, too, of the Greeks, were such as to favour the development of arts and sciences; among them-and perhaps especially-that of medicine. The gymnastic exercises, which formed so prominent a purt in the physical education of the Greeks, cannot but have favoured that state of vigorous health, without which mental powers of the highest order can scarcely be applied to their full advantage. Contrast the slow march in science and art made by languid weakly beings, with the pro gress made by robust healthy men, whose athletic development of body must have, acting in conjunction with other favouring circumstances, communicated an astonishing energy to the mental faculties. These gymnastic exercises had also another and more direct bearing on medicine; for their object was the preservation of health, while that of medicine was the cure of disease. The directors and employés of the gymnastic establishments even had the name of physicians, because they undertook the treatment of slight maladies. In this way, they gradually encroached on the monopoly of the priests.

I have referred to the Grecian colonies of Ionia in Asia Minor as having especially been favoured by the causes which would promote intellectual development. The same causes, in general, as influenced them, acted on the European Greeks; these latter, however, were slower than their Asiatic countrymen in perceiving the importance of scientific knowledge; but, when they did perceive it, the advance they made was great and most rapid. It is in Ionia that we find medicine first advancing towards its escape from mystery; and it is in that country also that appeared the earliest of those philosophers who so greatly modified the aspect of general science, and who exerted an especial influence on the progress of the science of medicine. Of the nature of this influence, $I$ will endeavour now to give you an outline.

The Grecian philosophy was in its origin speculative; allied to, and in all probability the offspring of, poetry. The questions first seized for discussion were not those relating to statistics and legislation or other tangible matters; but the speculations of the philosophers were employed on such theories as the origin of the world, the nature of the Deity and of the soul, the size and motions of the celestial bodies. And, for all these subjects, the materials existed in the national poetry-such, for instance, as the works of Hesiod. The oldest philosophical speculations were, in fact, the poetical doctrines in a somewhat new dress.

But, with the speculations on the nature of the human soul, the theory of the nature of the functions of the body was of necessity intimately connected. Hence the philosophers at a very early period began to inquire into-or rather to form hypotheses regarding - the processes of respiration, digestion, and generation, and the nature of the senses; as well as on the manner in which diseases are provoked by their causes. The theory of medicine-physiology and pathology-was then, at its starting, a part of general philosophy; and to the first development of physiological science I will now call your attention. We find its earliest traces, indeed, in the speculations of Thales of Miletus on the formation of matter; but, for practical purposes, we may give to Pythagoras and his disciples the credit of having directed attention to the explanation of the functions of the healthy body. This philosopher, too wisely made the medical art an important auxiliary to the good of the state, instead of being a mere part of the worship of the divinities. His rules aimed at developing the menta faculties and bodily functions in such a way as to make their possessors useful citizens.

Pythagoras is said to have travelled much, in Asia, Phenicia, and Egypt; and it seems pretty cleax, that from the Egyptians he borrowed the use of several medicines, and the strict sani tary rules which guided his community; and further, the sym. bolic language with which he enveloped his ideas from the un initiated was the same as that which was employed in Egypt.

Crotona, in Magna Grecia, is celebrated as the scene of the teachings of Pythagoras. Here this philosopher founded a society of persons to be instructed in the knowledge which he had acquired, and to carry out his plans for the reformation of the state. The sanitary regime under which this society lived was strict, and in many respects of an Egyptian cast, while it presented also an admixture of Grecian customs. The dis. ciples of Pythagoras were obliged to undergo daily certain bodily exercises, such as walking, wrestling, running, and dancing. Sobriety was a principal obligation; and the choice of the kind and quantity of aliments was most rigorously de fined. Many articles were probably forbidden on account of their liability to be abused by the voluptuous inhabitants of Magna Græcia, or because they were forbidden in the sacred mysteries of the Egyptians. Pythagoras and his disciples have had the reputation of being vegetarians. This, however, seems incorrect, as they are related to have used the flesh of animals in general, except fish. Their use of animal food, however, was very moderate. Moderation is inculcated as a fundamental maxim in the 'E $\tilde{\eta} \tau \alpha \chi \rho \nu \sigma \hat{\alpha}$, or Golden Verses, of the Pythagoreans.

"Nor is it right to be careless of the health of the body;

But in drink and meat, and in gymnastics,

Exercise moderation; I call that moderation, which will not harm thee."

The physical philosophy of Pythagoras has been too much mixed up with the notions of later writers for us to obtain an exact idea of his opinions. He held, however, the principle that the existence and well being of things depended on a harmony, comparable to that of numbers-a doctrine which has had some influence on subsequent medical theories, having probably laid the foundation of the doctrine of critical days in diseases. He taught that the odd numbers were determinate, and the even indeterminate; thus two, or the duad, was the symbol of undeterminate matter, or chaos; on this acted, or was added thereto, urity, or the monad, the determining force, which produces order; and from these resulted the determinate triad, or created nature. It seems that Pythagoras held the principal of life to reside in caloric, and that of motion in ether or air. Health was defined by Pythagoras to be a continuation of the primitive constitution, and disease as the derangement of that constitution. The same doctrine was taught by him of all that is good in any respect; so that by harmony he meant the relation or just proportion which all parts ought to have together.

As far as can be learned of the physiology and psychology of Pythagoras, he regarded the human suul as composed of two parts-the one rational ( $\phi \rho \in \nu \in S$ ), seated in the brain; the other irrational ( $\theta v \mu o s)$, seated in the heart. This idea was possibly derived from his having observed headache as a com. mon result of intense application to study, and palpitation of the heart as an effect of mental emotion. By more modern writers, a further subdivision of the non-reasonable part of the soul was made into two faculties-that of love, seated in the heart; and that of hatred, seated in the liver. This localisation of these two faculties, however, was sometimes reversed.

The practice of medicine is said to have been followed by Pythagoras; and it partook in his hands of the mystic cha. racter which it had in the hands of the priests of Egypt and of the Asclepiads. He had borrowed much of his knowledge from Egypt, where magic, divination, the interpretation of dreams, and medicine, were all combined in one pseudo. science. And the material on which Pythagoras had to exercise this mystic medicine was well fitted for it; for the inhabitants of Italy believed that the whole of nature was filled with deities. In accordance with this idea, the Pythagoreans taught that the spirits which hovered in the air, the demons, and the manes of departed heroes, sent dreams which furnished the explanation of diseases, and of the means of cure; but that expiatory and purificatory sacrifices were necessary in order to obtain the aid of these beings. He was acquainted with the action of certain medicines; and, according to some accounts, sometimes em ployed them independently of superstition, although in many cases he attributed to them magic virtues.

Beyond the importance which Pythagoras attached to hygienic measures, his merit lies in having given an impulse to a series of inquiries into the laws of physiology. The results of this come out more plainly in the records of the doctrines and labours of some of his followers. 
The medical practice of the Crotoniat physicians, the disciples of Pythagoras, was such as to gain them the reputation, according to Herodotus, of being the best practitioners in Greece. They are reputed, however, to have shunned surgical operations.

We now meet, among the disciples of the Pythagorean school, with some of the earliest recorded traces of a special study of the structure and functions of the body; not of the human body, except by analogy; for you must again remember that the ancient prejudices against meddling with the bodies of the dead long presented an obstacle against the study of anatomy ; and therefore, when in this lecture and in subsequent ones, until I shall have occasion to state otherwise, I speak of dissections, you must understand them to have been made on animals.

[To be continued.]

\section{Britinal Communitations.}

\section{THE MANAGEMENT OF THE PLACENTA.}

By W. Newrian, M.D.Lond., Fulbeck, Grantham.

So much of the ultimate safety of the patient in a case even of thoroughly natural labour, depends on the proper removal of the placenta, that I am disposed to offer some remarks on a mode of practice somewhat differing from the general routine taught in the schools, in the hope that the publication may not be without some advantage. I have for some years known and as constantly put in practice the plan I wish to mention. More than three hundred cases have passed under my notice during this time; and this number will probably be deemed sufficient basis for some practical conclusions.

The plan I adopt is as follows. After the expulsion of the child and the division of the umbilical cord, the patient still lying in the usual position on the left side, I at once carry my left hand over the right ilium, and so ascertain the condition of the uterus by manual examination through the abdominal parietes, without any delay.

Should the organ be thoroughly contracted, and the placenta fairly extruded from the cavity, it only remains to extract the mass with the right hand from the vagina.

If, however, the uterus be flaccid, uncontracted, and increasing in size, I immediately commence and keep up with the left hand firm yet not severe pressure upon the organ, until the progressive shrinling of its bulk induces the expulsion of the contained coagula, and the close compression of the placental mass. I ther wait some five or ten minutes before any further means are resorted to.

Again, should the uterus be found on examination firmly contracted, embracing the placenta, there will not exist any necessity for immediate manual compression.

After, however, the lapse of the time above specified, I again examine the abdomen with the left hand, grasping the uterus, as already described. This is done whether the organ be firmly contracted or the reverse, whether the placental mass have in part or not in any degree descended into the vagina. I do not wait in anxious expectation for the extrusion of the mass by the uterus sua sponte; nor, on the other hand, do I extract it from the uterine cavity by the employment of undue force; but I simply expel it from the interior of the uterus by external pressure, first exciting, then aiding, the natural action of the uterine walls. The placental whole is thus squeezed into the vagina with the coagula as yet mechanically detained behind it; thence I withdraw it, seizing it with the fingers of the right hand usually by a free edge, keeping up unremittingly with the left hand the same compression upon the uterus, until the complete removal is effected. I rarely make use of, and never trust to, the umbilical cord for the withdrawal of the placenta.

The advantages I believe to be thus secured, are:-

1. The certainty as to the actual state of the uterus.

2. The control thereby obtained over the quantity of blood poured out during the process of detachment of the placenta.

3. The ultimate attainment of complete uterine contraction.

4. The almost complete emptying of the uterine cavity from coagula, etc.
5. The much increased certainty ; that concealed or post partum hæmorrhage will not occur.

6. The absence of hour-glass contraction or undue detention of the placenta.

Objections will probably be raised to the carrying out of this plan, on the score of undue exposure of the person, and of the hazard that the requisite manipulation may inflict some injury on the uterine substance. I do not think that either of these objections should outweigh the increased safety of the lying-in woman; and I may almost say that they have hardly any foundation. The whole process may be carried on easily beneath the bed-clothes; and the amount of bruising and rough treatment which the already effete and comparatively insensible uterine structure will with impunity bear in cases of difficult version, may well lead one to ignore the possibility of injury from the simple and external compression.

Authors, as a rule, recommend patiently waiting until the placenta shall have passed into the vagina by unaided uterine effort, and then extracting the mass from that canal by gentle traction at the cord; while the application of external pressure through the abdominal walls is usually named only as a useful adjunct to other means in the treatment of flooding.

I would venture to suggest that the latter expedient be made in every-day practice the rule and not the exception; and the result will, I believe, prove the correctness of the opinion.

\section{ULCERATION OF THE LOWER EXTREMITY OF THE RECTUM ; ITS VARIETIES, DIAGNOSIS, AND TREATMENT.}

By James Rouse, Esq., Assistant-Surgeon to the Westminster Ophthalmic Hospital, and Surgical-Registrar to St. George's Hospital.

Notwithstanding the numerous works published on diseases of the rectum during the last few years, there appears still to be great difference of opinion as to the best mode of treatment; more particularly with regard to those ulcerations situated on the mucous membrane lining the sphincter ani, and in the fossa immediately above that muscle.

There are three forms of ulceration of the lower extremity of the rectum, which give rise to very acute suffering; and, although they vary considerably in position, have nevertheless been described by most authors under the general head of fissure. It is proposed, in the present paper, to point out that three distinct forms of ulceration occur in this region, which, by ordinary investigation, may be distinguished from each other, and which require different modifications of treatment.

The most common form of ulcer found at the lower extremity of the rectum is that which is known as fissure of the anus. This disease does not seem confined to any particular period of life, though it rarely or ever exists until after puberty. It is more particularly common among persons who lead a sedentary life, and for the same reason it is rather more frequent in women than men. The fissure appears to be caused by a tearing of the mucous membrane lining the sphincter ani, by the passage either of hardened fæces, or of a foreign body contained therein. The following cases will, however, show that fissure of the anus may occasionally be the result of external violence :-

CASE I. A gentleman, aged 24, was riding a restive horse, when it suddenly bolted. He was thrown, with some violence, on the hind part of the saddle before he recovered his seat. He felt some pain about the anus at the time, and, on changing his shirt, he noticed a few drops of blood. For the next few days he experienced a slight burning pain during the evacuation of the bowels, and in about a week the characteristic pain of fissure was established. On an examination being made, a small crack was perceived on the posterior surface of the sphincter; it commenced about two lines within the anus, and extended upwards for about half an inch. Various local means were tried without benefit, and an operation, to be hereafter described, was had recourse to with perfect success.

CASE II. A captain in the navy fell off a ladder, and came to the ground on his buttocks, with considerable force. He did not observe any particular pain until he went to stool the following morning, when he experienced considerable smarting, and noticed that he had passed a small amount of florid blood. About a week after the accident, he applied for advice. He 